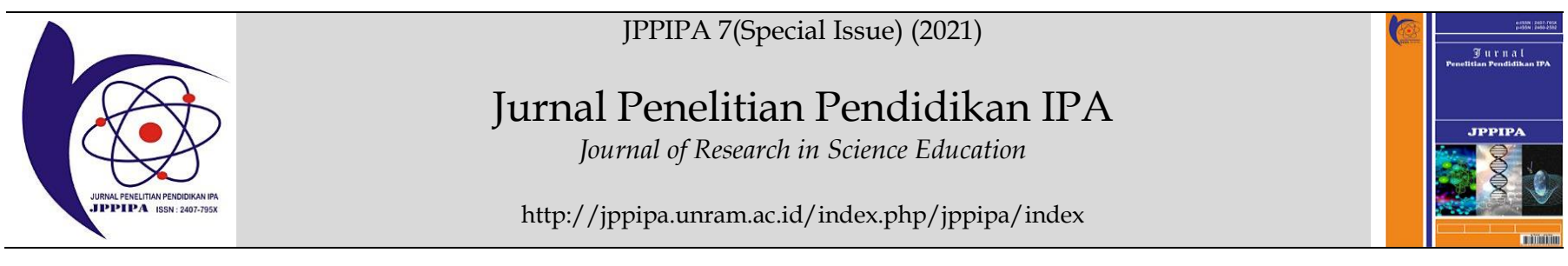

\title{
Characterization of PVA-Enzyme Coated Indicator Electrodes GA coated again with PVC-KTpClPB-o-NPOE UV-Vis analysis, variable signal analysis, sensor sensitivity and SEM-EDS
}

\author{
Abd Hakim S1* \\ ${ }^{1}$ Department of Physics, Faculty of Mathematics and Natural Sciences, Universitas Negeri Medan, Indonesia
}

DOI: $10.29303 /$ jppipa.v7iSpeciallssue.1248

\section{Article Info}

Received: November $16^{\text {th }}, 2021$

Revised: December 24th, 2021

Accepted: December 26th 2021

\begin{abstract}
This study aims to characterize the phosphate buffer and urease enzymes through UV-Vis and SEM-EDS absorbance spectra using tungsten as an indicator electrode. The method used is a potentiometric biosensor with urease enzyme immobilization technique for urea analyte. A small detection range of 10-5-10-4M has been studied with PVA-enzyme coated indicator electrodes coated with PVC-KTpCIPB. On this basis, the researchers increased the detection range by analyzing glutaraldehyde (GA) mixed with PVA-enzyme and o-NPOE mixed with PVC-KTpCIPB. The best results of GA mixed PVAenzyme at GA2.9\% UV-Visible analysis. The best results were PVA-enzyme coated indicator electrodes coated with GA coated again with PVC-KTpCIPB-o-NPOE SEM-EDS analysis on PVA-enzyme samples $3 x$ coated with GA $1 x$ and PVC-KTpCIPB-o-NPOE 1x with o-NPOE variation of $61 \%$ and $66 \%$.
\end{abstract}

Keywords: UV-Visible and SEM-EDS; GA and o-NPOE; tungsten indicator electrode; Biosensor potentiometry; Immobilization.

Citation: Hakim S.A. (2021). Characterization of PVA-Enzyme Coated Indicator Electrodes GA coated again with PVCKTpCIPB-o-NPOE UV-Vis analysis, variable signal analysis, sensor sensitivity and SEM-EDS. Jurnal Penelitian Pendidikan IPA, 7(SpecialIssue), 370-376. https://doi.org/10.29303/ippipa.v7iSpecialIssue.1248

\section{Introduction}

Research has been carried out on indicator electrodes coated with PVA-enzyme coated with PVC$\mathrm{KTpCIPB}$ with a detection range of $10^{-5}-10^{-4} \mathrm{M}$ (Hakim, 2019). This electrode analysis has been characterized using SEM-EDS (Hakim, 2018). Range $5 \cdot 10^{-7}-10^{-2} \mathrm{M}$, according to (Rahman, 2008), on this basis the researchers increased the detection range with GA and o-NPOE.

GA has been shown to be effective in increasing the strength and thermal stability of gelatin films (Lin, 2020). GA as a crosslinker enhances the properties of the ionogel, achieving a 5-fold higher activity than the free enzyme and also for reuse at $70^{\circ} \mathrm{C}$. The chemical composition and morphology were studied by electron microscopy SEM spectroscopy and energy dispersive X-ray EDS (Escudero, 2020).

Glutaraldehyde (GA) prevents the loss of enzymes in repeated use of the adsorbent and increases the stability of the enzymatic function to unchanged activity in 18 cycles (Pogorilyi, 2017). When used 5\% wt immobilized urease with glutaraldehyde.

Increasing or decreasing activity, 3\% glutaraldehyde concentration causes a decrease [Kayastha and Srivastava, 2001], as well as the optimal glutaraldehyde concentration between $2.5-3 \%$ for urease immobilization. The technique used is adsorption, entrapment, crosslinking. The cross-linking technique (Ismaiel et al., 2015) contributes to strengthening the biocatalyst bond, preventing leakage, reducing desorption and increasing the stability of the biocatalyst.

\footnotetext{
*Email: abdhakims@unimed.ac.id
} 
2-nitrophenyloctyl ether (NPOE) has been used and mixed in poly (vinyl chloride) (PVC) (Huang, 2014) on ion-selective electrodes. The sensitivity is 19.7 $\mathrm{mV} /$ decade with a range of $5 \cdot 10^{-7}-10^{-2} \mathrm{M}$, according to (Rahman, 2008) the optimum sensitivity is 59 $\mathrm{mV} /$ decade. The potential difference between the reduction and oxidation peaks is theoretically $59 \mathrm{mV}$ (Rahman, 2008) for a reaction that is reversible, in practice the difference is typically between $70-100 \mathrm{mV}$.

The immobilization technique for biosensor construction involves the urease enzyme into a polymer consisting of PVC for the urea bioser (Ulianas, Heng, and Ahmad, 2011). Poly (vinyl chloride) (PVC) is a polymer matrix commonly used in ISE (Mir, et al., 2014).

The PVC within the permissible limits provided the membrane electrode having the composition of PVC: o-NPOE: DPA: NaTPB as 33:61:3:3 (w/w) as the optimum composition with the closest Nernstian response (Kaur, Chhibber and Mittal, 2017). Composition 30:65.5:0.5 mg PVC: o-NPOE: KTpClPB (Badakhshan, 2019), about the composition of PVC, plasticizers and lipophilic additives. Ionophores (I) $1.10 \%(w / w)$, lipophilic salt (KTpClPB) $0.25 \%(w / w)$, plasticizer (o-NPOE) $65.65 \%(\mathrm{w} / \mathrm{w})$, and PVC $33.00 \%$ $(\mathrm{w} / \mathrm{w})$ dissolved in tetrahydrofuran (Lenar, 2020).

The organic solvents tetrahydrofuran (THF), dimethylformamide (DMF), and ethylene glycol (Gly) were used for dispersion of coating materials and dissolving membrane components (Lenar, 2020). According to (Lenar, 2020) DMF is better than THF as an organic solvent.

Plasticizer (either DOP or o-NPOE, $133 \mathrm{mg}$ ), and PVC (66 mg) in THF (3 mL) (Elbehery, 2019). The DOPcontaining membranes provided a lower detection limit and a wider linearity range than those containing the oNPOE plasticizer.

Based on the information above, the researcher developed a membrane modification indicator electrode. The design of the PVA-Enzyme-coated tungsten indicator electrode design was further coated with PVC-KTpCIPB-o-NPOE. The method used is potentiometric biosensor immobilization technique of urease enzyme for urea analyte. The electrodes were designed in two ways at $61 \%$ and $66 \%$ o-NPOE variations. First, the electrodes were coated with PVAEnzyme 1x coated with GA 1x coated again with PVCKTpCIPB-o-NPOE 1x, denoted A1-4 61\% and A1-466\%. Both coated with PVA-Enzyme $3 x$ coated with GA $1 x$ coated again with PVC-KTpCIPB-o-NPOE $1 x$, notated A3-4 61\% and A3-4 66\%.

\section{Method}

The materials used in the manufacture of the indicator electrodes were tungsten with a diameter of $1.0 \mathrm{~mm}$ 99.99\% Aldrich 267562, PVA [- $\left.\mathrm{CH}_{2} \mathrm{CHOH}-\right] \mathrm{n}$, enzyme EC 3.5.1.5 (Urease) U4002, 50 - 100 ku type ix, glutaraldehyde (GA); PVC $\left(\mathrm{CH}_{2} \mathrm{CHCl}\right) \mathrm{n}$, potassium tetrakis (4-chlorophenyl) borate (KTClPB), onitrophenyloctylether (o-NPOE), Tetrahydrofuran $\mathrm{C}_{4} \mathrm{H}_{8} \mathrm{O}$; Phosphate Buffer $\mathrm{KH}_{2} \mathrm{PO}_{4}, \mathrm{KCl}$, urea standard 56180, from Sigma-Aldrich.

Also used is a potentiometer cell equipped with an Ag/AgCl MF-2052 RE-5B reference electrode and a design indicator electrode coupled with a microcomputer (ADI Powerlab instrument, Australia), magnetic stirrer and flow injection (FIA).

The indicator electrodes were made by using the potentiometric biosensor of the urease enzyme immobilization technique in two notations B1-4 2.9\% GA and B3-4 2.9\% GA. Then it was analyzed with a potentiometer cell containing a solution of $0.001 \mathrm{M}$ $\mathrm{KH}_{2} \mathrm{PO}_{4}+\mathrm{KCl} \mathrm{pH} 7.5$, with urea injection variations of $10^{-7}-10^{-1} \mathrm{M}$ and variable signal analysis. From the two samples above, it was continued to manufacture four indicator electrodes with notation A1-4 61\%, A3-4 61\% and A1-4 66\%, A3-4 66\%. Then all four were analyzed by SEM-EDS.

\section{Result and Discussion}

Results of UV-Vis Characterization of PVA-E-GA Solution

Experimental research on PVA-Enzyme solution mixed with GA has been carried out with UV-Vis analysis between $2.5-3 \%$. The best results can be seen in Figure 1 of the PVA-E-GA solution, at $2.9 \%$ GA.

On the basis of the best results of PVA-E-GA $2.9 \%$, the indicator electrode was modified through the membrane with the following design: first, the PVA-EGA solution was coated $1 x, 2 x$, and $3 x$ coated again with PVC-KTpCIPB 1x, notated A1-4, A2-4 and A3-4. The best results are at electrodes A1-4 and A3-4.

The two solutions of PVA-E 1x, 2x, 3x were coated with GA, $1 x$ was coated again with PVCKTpCIPB 1x, given the notations B1-4, B2-4 and B3-4. The best results are at electrodes B1-4 and B3-4.

XRD analysis of the electrodes has been carried out in a first way, A1-4 high peak intensity 270 u.a at $44.28^{\circ}$, A3-4 high peak intensity 382 u.a at $44.32^{\circ}$. The second way B1-4 high peak intensity 452 u.a at 44.32 , B3-4 high peak intensity 286 u.a at $44.34^{\circ}$. The best result in the second method is PVA-E coated with GA coated again with PVC-KTpCIPB. There are differences in the cross method and the entrapment method is better than the entrapment method [Bhushan, Pal and Jain, 2015]. This second method was followed by 
modification of PVC-KTpCIPB plus o-NPOE at variations of $61 \%$ and $66 \%$.

The three solutions of PVA-Enzyme $1 x$ were coated with GA $1 x$ again coated with PVC-KTpCIPB-oNPOE $1 x$, with variations of o-NPOE $61 \%$ and $66 \%$ given the notations A1-4 61\% and A1-4 66\%; in the same way the PVA-Enzyme solution 3x coated with GA $1 x$ was coated again with PVC-KTpCIPB-o-NPOE $1 \mathrm{x}$, given the notations $\mathrm{A} 3-461 \%$ and $\mathrm{A} 3-466 \%$.

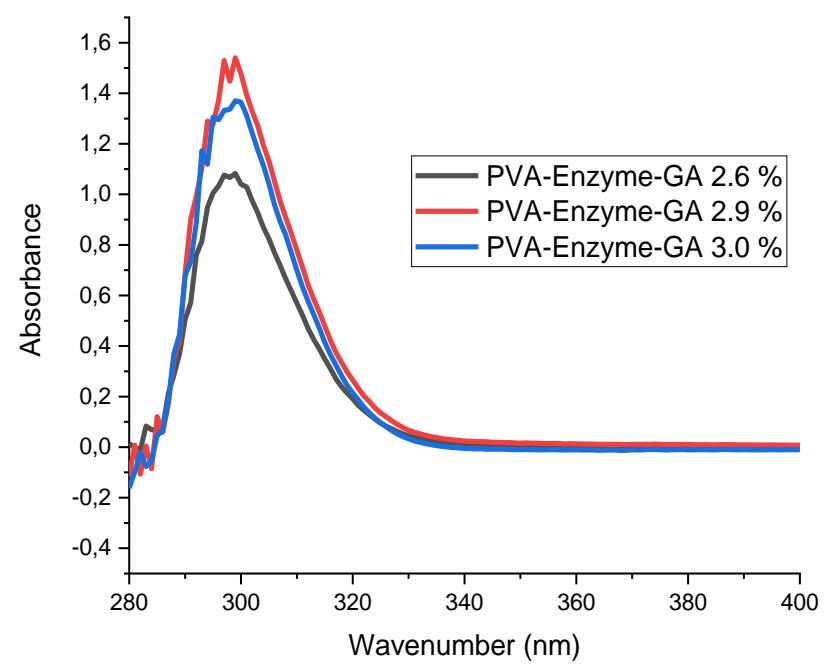

Figure 1. The best PVA-Enzyme-GA absorbance spectrum pattern is at $2.9 \%$, with different absorbance peak heights.

\section{Variable Signal Analysis Characterization Results}

According to the second method, the indicator electrodes were analyzed using a potentiometer cell consisting of the RE-5B Ag/ AgCl MF-2052 reference electrode and the tungsten indicator electrodes B1-4 Figures (2a and 2b) and Figures B3-4 (3a and 3b).

The potentiometer cell used a buffer solution of $0.001 \mathrm{M} \mathrm{KH} 2 \mathrm{PO} 4+\mathrm{KCl} \mathrm{pH} 7.5$ with a variation of $10^{-7}$ $10^{-1} \mathrm{M}$ urea injection. The best results were obtained at the indicator electrode B1-4 based on the signal analysis of the variable in Figure 2a. and the sensitivity was $46.69 \mathrm{mV} /$ decade, the detection range was $10 .^{-4}$ $10^{-2} \mathrm{M}$, and the detection limit is $10^{-4} \mathrm{M}$, the confidence coefficient $\mathrm{R}^{2}=99.62 \%$ Figure $2 \mathrm{~b}$. The best result of indicator electrode B3-4 is based on the analysis of the variable signal in Figure $3 a$ and the sensitivity is 38.16 $\mathrm{mV} /$ decade in the urea detection range of $10^{-6}-10^{-4} \mathrm{M}$, the detection limit is $10^{-46} \mathrm{M}$, the confidence coefficient $\mathrm{R}^{2}=95.42 \%$.
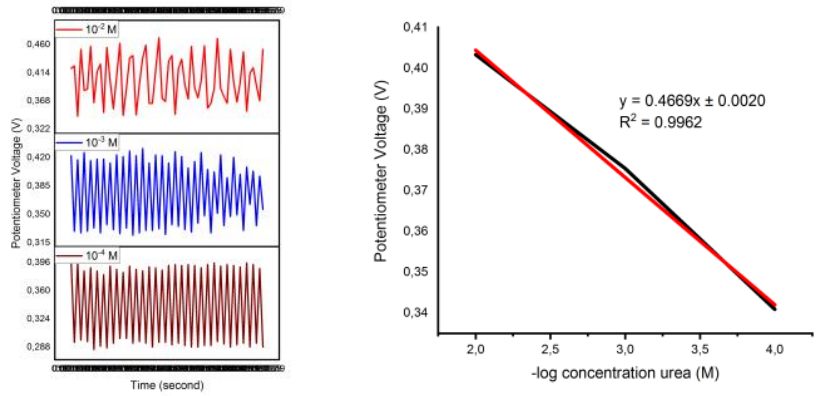

Figures $\mathbf{2 a}$ and $\mathbf{2 b}$. Analysis of the potentiometer cell variable signal and sensitivity $46.69 \mathrm{mV} /$ decade, detection range $10^{-4}$ -

$10^{-2} \mathrm{M}$ and detection limit $10^{-4} \mathrm{M}, \mathrm{R}^{2}=99.62 \%, \mathrm{~B} 1-4$.

The symmetry of the signal [Hakim, et al 2021] is very dependent on the incoming signal and outgoing signal from the redox process. The incoming signal is not the same as the outgoing signal with a total signal data of 400 signals/second [Kim, Liu and Payne. 2017]. The symmetry of the signal [Basile, Bhatt and O'Mullane, 2016] can be seen in Figure 2a and Figure $3 \mathrm{a}$. The voltage between the oxidation and reduction peaks according to [Rahman et al, 2008] is theoretically $59 \mathrm{mV}$ for a reversible reaction.
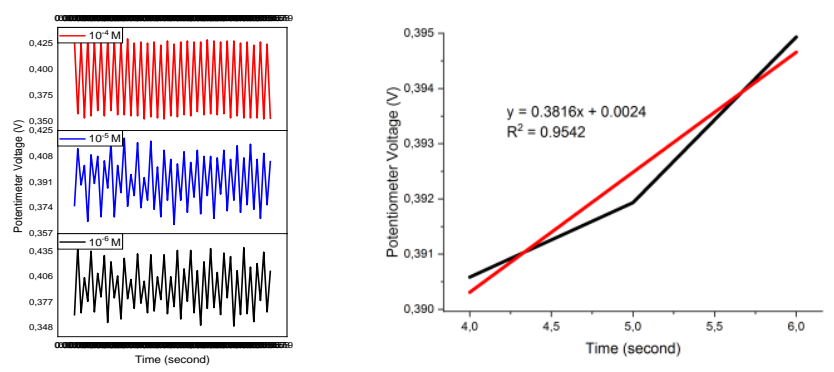

Figures $\mathbf{3 a}$ and $\mathbf{3 b}$. Variable signal analysis and sensitivity $38.16 \mathrm{mV} /$ decade, detection range $10^{-6}-10^{-4} \mathrm{M}$ and detection limit $10^{-6} \mathrm{M}, \mathrm{R}^{2}=95.42 \%, \mathrm{~B} 3-4$.

\section{Characterization Results of SEM-EDS B1-4 and B3-4}

The difference in the best results for indicator electrodes B1-4 and B3-4 was analyzed by variable signal analysis supported by SEM-EDS analysis in Table 1. that more weight percent, atomic percent and tungsten ratio on indicator electrode B3-4 than indicator electrode B1- 4. The second way is the best result according to [Bhushan, B., et al, 2015]. The first way is cross, the second way is entrapment. According to the EDS spectrum pattern and morphology of the indicator electrodes B1-4 and B3-4, there are differences in the spectrum and morphological patterns. Also accompanied by weight percent, atomic percent and atomic ratio can be seen in Table 1. 

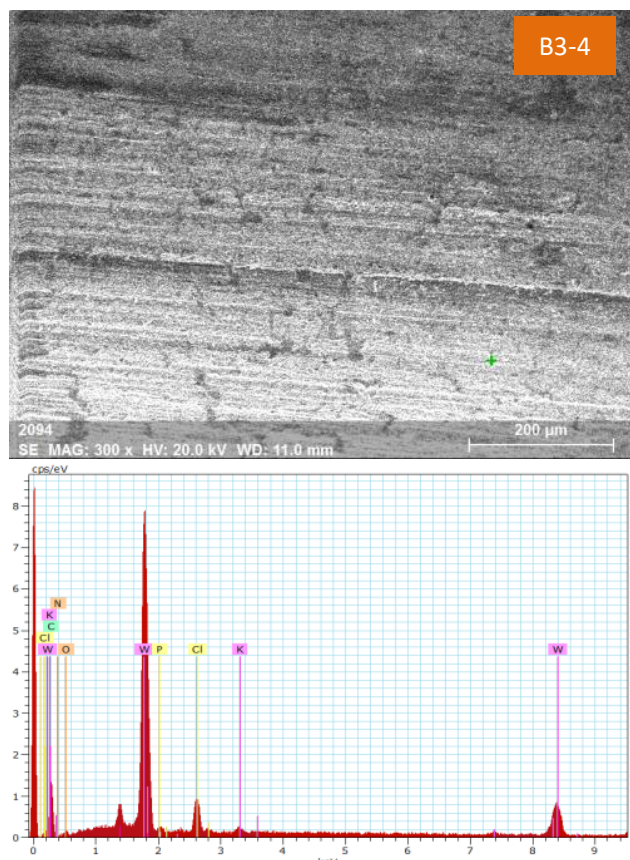

Figure 4. The morphology of the B3-4 indicator electrode and the EDS spectrum pattern.
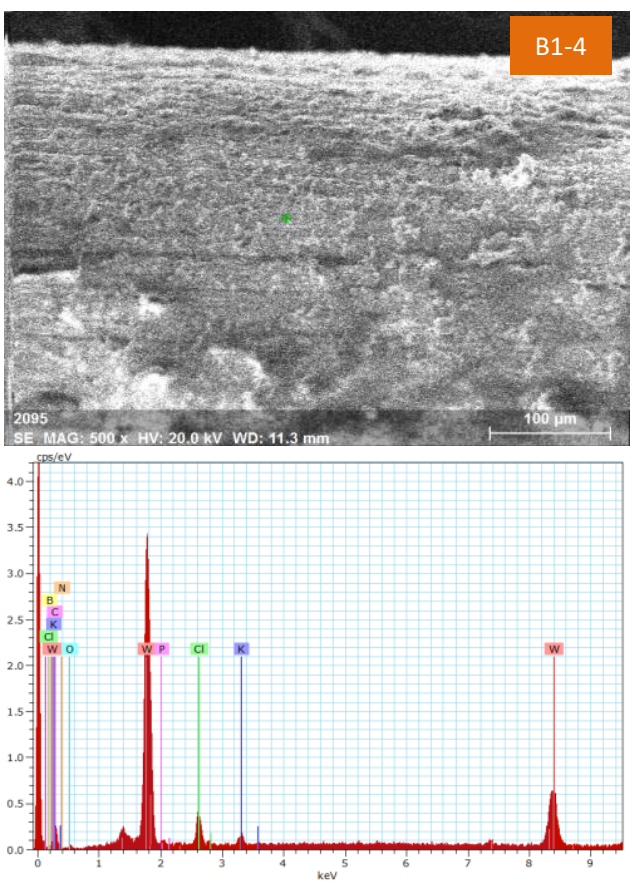

Figure 5. The morphology of B1-4 indicator electrodes and the EDS spectrum pattern.

B3-4 is an indicator electrode coated with PVA-E $3 x$ coated with GA 29\% 1x coated again with PVCKTpCIPB $1 x$ entrapment method. B1-4 is an indicator electrode coated with PVA-E 1x coated with GA $2.9 \%$ $1 x$ coated again with PVC-KTpCIPB $1 x$ entrapment method.
Table 1. Weight percent, atomic and atomic ratio of Tungsten without o-NPOE.

\begin{tabular}{lllll}
\hline $\begin{array}{l}\text { Indicator } \\
\text { electrode }\end{array}$ & Element & Weight \% & Atomic\% & $\begin{array}{l}\text { Ratio } \\
\text { Atomic }\end{array}$ \\
\hline B1-4 & w & 73.68 & 80.30 & 2.41 \\
B3-4 & w & 76.24 & 87.78 & 2.49 \\
\hline
\end{tabular}

Results of UV-Vis Characterization of PVC-KTpClPB-oNPOE Solution.

Membranes containing o-NPOE as a plasticizer with a higher dielectric constant $(\varepsilon=24)$ showed the best Nernstian response (Badakhshan, 2019). Membranes containing DOP provide lower detection limits and a wider linearity range than those containing the o-NPOE plasticizer (Elbehery, 2019).

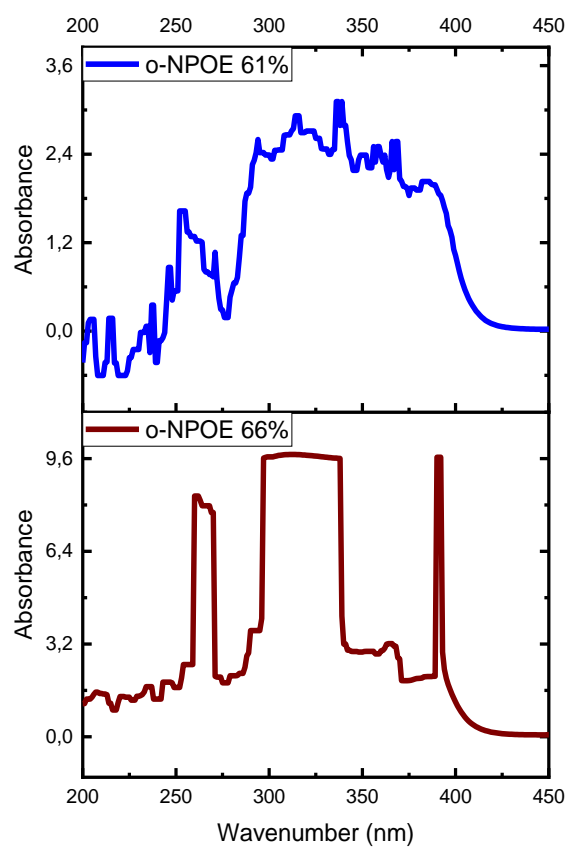

Figure 6. Absorbance spectrum pattern of PVC-KTpClPB-oNPOE at o-NPOE $61 \%$ and $66 \%$.

When compared to Figure 1, the UV-Vis absorption spectrum pattern of PVA-E-GA solution and PVC-KTpCIPB-o-NPOE solution at o-NPOE 61\% and $66 \%$. In the PVA-E-GA solution, the absorbance peak is around $300 \mathrm{~nm}$ and the wavelength is $280-320$ $\mathrm{nm}$. In the PVC-KTpCIPB-o-NPOE solution with $61 \%$ o-NPOE, the absorbance peak height was about 250 with a wavelength range of $200-235 \mathrm{~nm}$ and an absorbance peak height of about 337.5 with a wavelength range of $235-425 \mathrm{~nm}$.

In the PVC-KTpCIPB-o-NPOE solution with $66 \%$ o-NPOE, the absorbance peak height was about 250 with a wavelength range of 200-265 nm, the absorbance peak height was about 348 with a wavelength range of $265-370 \mathrm{~nm}$, and the absorbance 
peak height was about 380 with a wavelength range. wavelength $370-400 \mathrm{~nm}$.

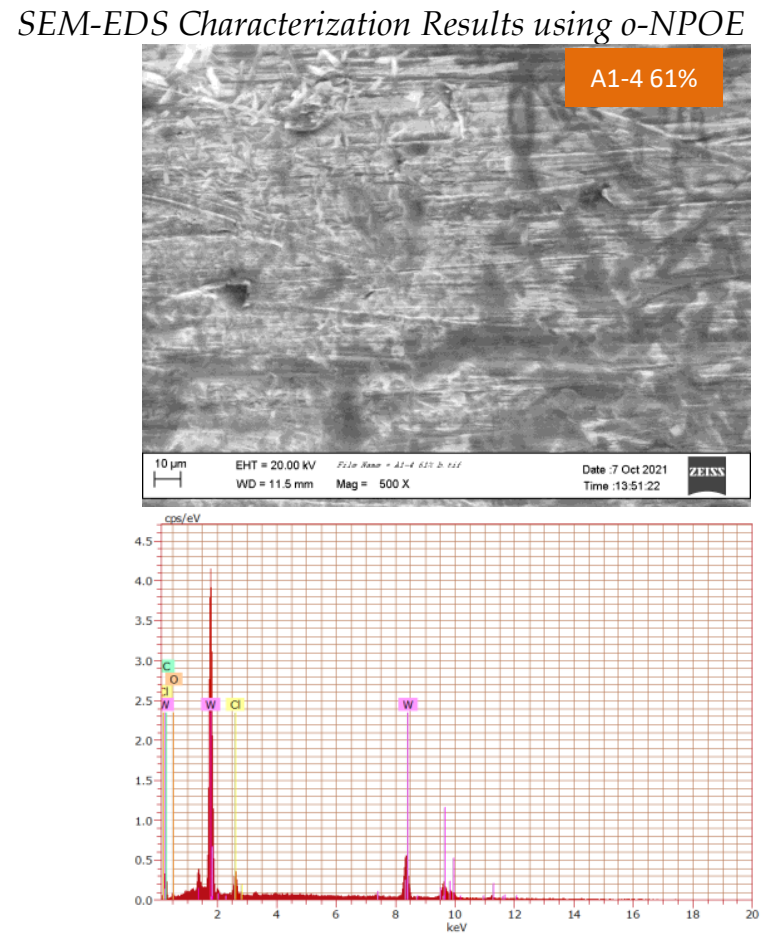

Figure 7. The morphology of the A1-4 61\% indicator electrode and the EDS spectrum pattern.

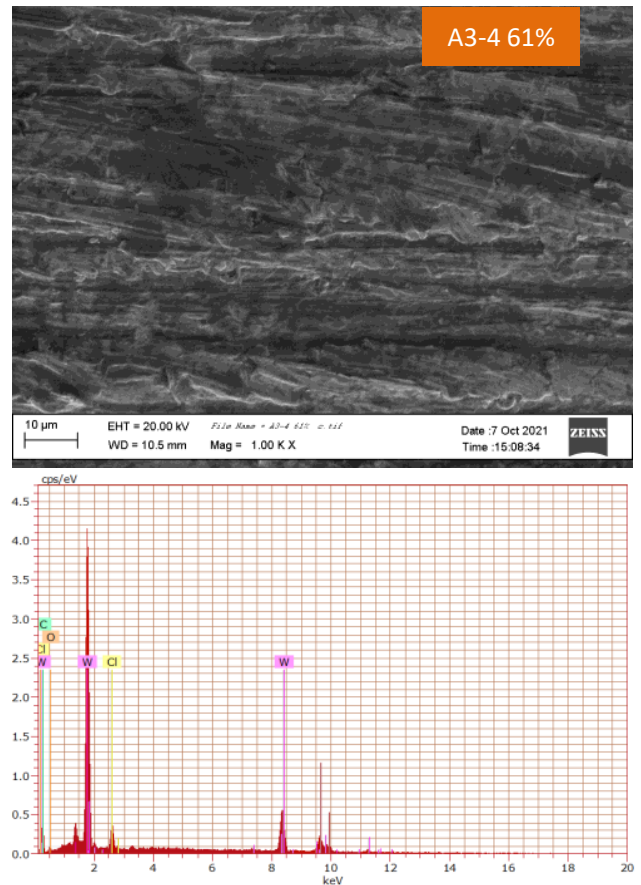

Figure 8. Morphology of A3-4 61\% indicator electrode and EDS spectrum pattern.

Increasing the wavelength range affects the linear range. This can be seen in the EDS spectrum pattern in Figure 4. B3-4 indicator electrode and Figure 5. B1-4 indicator electrode without o-NPOE with o-
NPOE Figure 7, 8, 9 and 10. In Figures 4 and 5 the spectrum pattern ranges from the scale 0-9 without oNPOE. In Figure 7-10 the spectrum pattern from 0-10 scale with o-NPOE, is also followed by the pores of the morphology getting clearer and bigger.

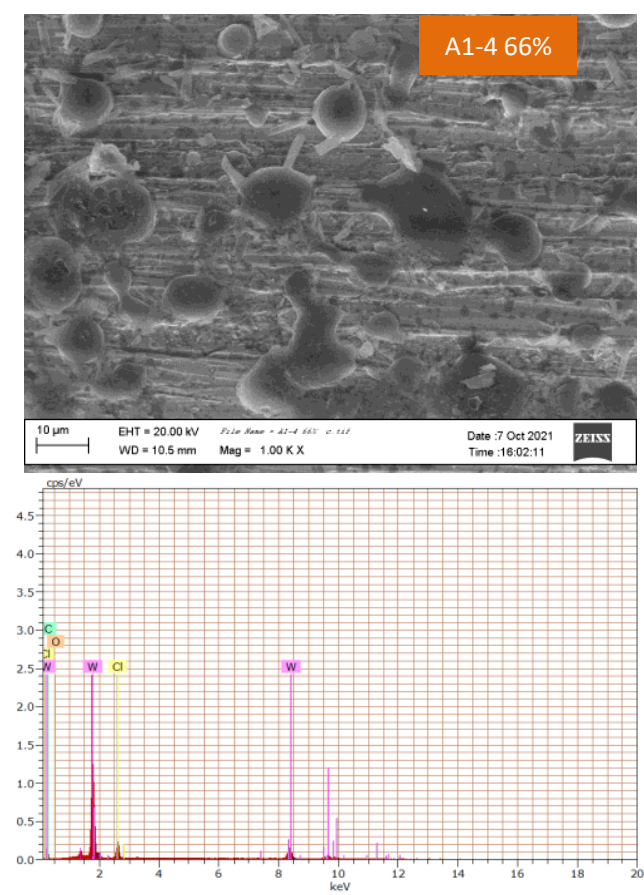

Figure 9. Morphology of A1-4 66\% indicator electrode and EDS spectrum pattern.

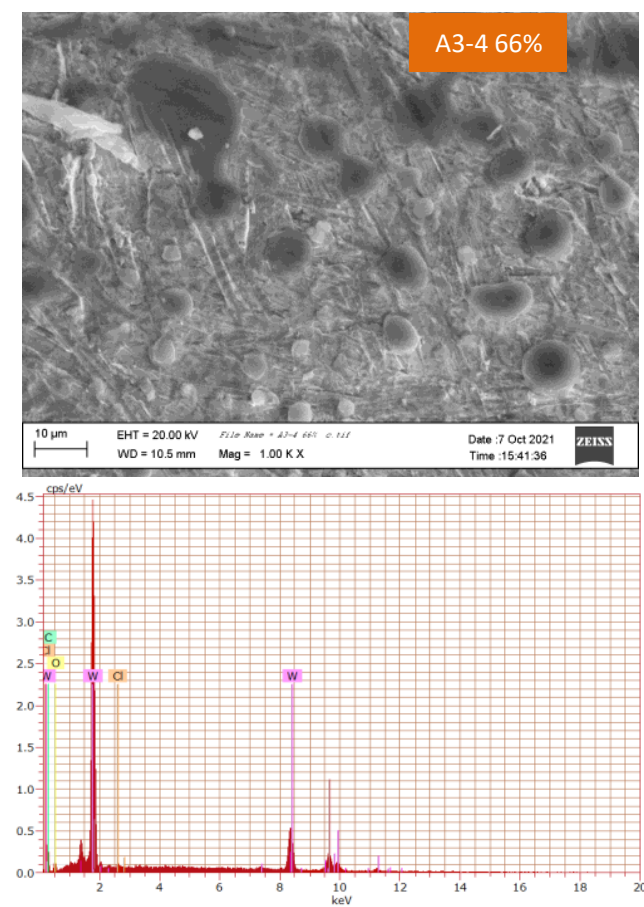

Figure 10. The morphology of the indicator electrode A3-4 66\% and the EDS spectrum pattern.

According to Table 1. indicator electrode B3-4 is better than indicator electrode B1-4, but based on 
variable signal analysis and sensitivity indicator electrode B1-4 is better than indicator electrode B3-4 without o-NPOE.

When followed the analysis of Table 1 and the analysis of the EDS spectrum pattern in Figures 3. and 4. Likewise, Table 2. with samples A1-4 61\%, A3-4 61, A1-4 66\% and A3-4 66\% analysis of the EDS spectrum pattern Figure 7-10. The tendency of the best sample is A1-4 66\% with the smallest weight percent, atomic percent and atomic ratio of tungsten.

Table 2. Weight percent, atomic and atomic ratio of Tungsten Using o-NPOE.

\begin{tabular}{lllll}
\hline $\begin{array}{l}\text { indicator } \\
\text { Electrode }\end{array}$ & Element & $\begin{array}{l}\text { Weight } \\
\%\end{array}$ & $\begin{array}{l}\text { Atomic } \\
\%\end{array}$ & $\begin{array}{l}\text { Ratio } \\
\text { Atomic }\end{array}$ \\
\hline A1-4 61\% & w & 91.91 & 91.80 & 2.93 \\
A3-4 61\% & w & 95.98 & 92.78 & 3.04 \\
A1-4 66\% & w & 84.93 & 86.27 & 2.74 \\
A3-4 66\% & w & 79.81 & 87.45 & 2.59 \\
\hline
\end{tabular}

\section{Conclusion}

Based on the data above, the manufacture of tungsten indicator electrodes with the best membrane modifications at B1-4 and A1-4 66\%. B1-4 membrane consists of $1 x$ PVA-E coated GA $1 x$ coated PVCKTpCIPB 1x. A1-4 66\% membrane consists of 1x PVA-E coated GA 1x PVC-KtpClPB-o-NPOE coated 1x.

\section{References}

Badakhshan, S., Ahmadzadeh, S., Mohseni-Bandpei, A., Aghasi, M., \& Basiri, A. (2019). Potentiometric sensor for iron (III) quantitative determination: experimental and computational approaches. BMC Chemistry, 13(1), 131. https://doi.org/10.1186/s13065-019-0648-x

Basile, A., Bhatt, A. I., \& O'Mullane, A. P. (2016). Stabilizing lithium metal using ionic liquids for long-lived batteries. Nature Communications, 7(1), ncomms11794.

https://doi.org/10.1038/ncomms11794.

Bhushan, B., Pal, A., \& Jain, V. (2015). Improved Enzyme Catalytic Characteristics upon Glutaraldehyde Cross-Linking of Alginate Entrapped Xylanase Isolated from Aspergillus flavus MTCC 9390. Enzyme Research, 2015, 210784. https://doi.org/10.1155/2015/210784.

Elbehery, N. H. A., Amr, A. E.-G. E., Kamel, A. H., Elsayed, E. A., \& Hassan, S. S. M. (2019). Novel Potentiometric 2,6-Dichlorophenolindophenolate (DCPIP) Membrane-Based Sensors: Assessment of Their Input in the Determination of Total Phenolics and Ascorbic Acid in
Beverages. In Sensors. 19(9). https://doi.org/10.3390/s19092058.

Escudero, A., de los Ríos, A. P., Godínez, C., Tomás, F., \& Hernández-Fernández, F. J. (2020). Immobilization in Ionogel: A New Way to Improve the Activity and Stability of Candida antarctica Lipase B. In Molecules. 25(14). https://doi.org/10.3390/molecules25143233

Hakim S.A., Sembiring, T, Tarigan, K., Sebayang, K., Situmorang, M., and Noer, N. M, (2019) Characterization of Membrane PVA-Enzyme Coated PVC-KTpCIPB as Urea Sensor with Potentiometric Method, Rasayan Journal of Chemistry, 12, 780-786. https://doi.org/10.31788/RJC.2019.1225143.

Hakim S.A., Situmorang, M., Sebayang, K., Sembiring, T., Tarigan, K., Mihardi1, S., Noor, N.M., and Elnovreny, J., (2021). Characterization Of Urea Analyte Solution and Electrolyte Solution Using Non-Immobilized Electrode Indicators and PvaEnzyme Coated Pvc-Ktpclpb Immobilization, Rasayan Journal of Chemistry, 14, 2021. https://doi.org/10.31788/RJC.2021.1426103.

Hakim S.A., Tarigan, K., Situmorang, M., \& Sembiring, T. (2018). Synthesis of Urea Sensors using Potentiometric Methods with Modification of Electrode Membranes Indicators of ISE from PVA-Enzymes Coating PVC-KTpClPB. Journal of Physics: Conference Series, 1120, 12024. https://doi.org/10.1088/17426596/1120/1/012024.

Huang, S., Luo, F., and Lai, X., (2014), Novel Potentiometric Sensors of Ion Imprinted Polymers for Specific Binding of Yttrium(III), Asian Journal of Chemistry; Vol. 26, No. 20 : 67876790.

https://doi.org/10.14233/ajchem.2014.16795

Ismaiel, A. A., Aroua, M. K., \& Yusoff, R. (2014). Cadmium (II)-selective electrode based on palm shell activated carbon modified with taskspecific ionic liquid: kinetics and analytical applications. International Journal of Environmental Science and Technology, 11(4), 1115-1126. https://doi.org/10.1007/s13762-013-0296-y.

Kaur, H., Chhibber, M., \& Mittal, S. K. (2017). Acyclic Arylamine-Based Ionophores as Potentiometric Sensors for $\mathrm{Zn} 2+$ and Ni2+ Ions. In C (Vol. 3, Issue 4). https:/ / doi.org/10.3390/c3040034.

Kim, E., Liu, Z., Liu, Y., Bentley, W. E., \& Payne, G. F. (2017). Catechol-Based Hydrogel for Chemical Information Processing. In Biomimetics 2(3). https://doi.org/10.3390/biomimetics2030011.

Lenar, N., Paczosa-Bator, B., \& Piech, R. (2020). Optimization of Ruthenium Dioxide Solid Contact in Ion-Selective Electrodes. In 
Membranes.

$10(8)$.

https://doi.org/10.3390/membranes10080182

Lin, J., Pan, D., Sun, Y., Ou, C., Wang, Y., \& Cao, J. (2019). The modification of gelatin films: Based on various cross-linking mechanism of glutaraldehyde at acidic and alkaline conditions. Food Science \& Nutrition, 7(12), 4140-4146. https://doi.org/https://doi.org/10.1002/fsn3.1 $\underline{282}$

Mir, M., Lugo, R., Tahirbegi, I. B., \& Samitier, J. (2014). Miniaturizable Ion-Selective Arrays Based on Highly Stable Polymer Membranes for Biomedical Applications. In Sensors 14(7). https://doi.org/10.3390/s140711844.

Pogorilyi, R. P., Pylypchuk, I., Melnyk, I. V., Zub, Y. L., Seisenbaeva, G. A., \& Kessler, V. G. (2017). SolGel Derived Adsorbents with Enzymatic and Complexonate Functions for Complex Water Remediation. Nanomaterials (Basel, Switzerland), 7(10), 298. https://doi.org/10.3390/nano7100298

Rahman, M. A., Kumar, P., Park, D.-S., \& Shim, Y.-B. (2008). Electrochemical Sensors Based on Organic Conjugated Polymers. Sensors, 8(1), 118-141. https://doi.org/10.3390/s8010118.

Ulianas, A., Heng, L. Y., \& Ahmad, M. (2011). A biosensor for urea from succinimide-modified acrylic microspheres based on reflectance transduction. Sensors (Basel, Switzerland), 11(9), 8323-8338. https://doi.org/10.3390/s110908323. 